\title{
The Impact of Logic of Marketing Research on Marketing ROI: Theoretical Analysis and Empirical Investigation
}

\author{
Wael Kortam \\ Cairo University, Egypt \\ Ghada Gad \\ Canadian International College, Egypt

\section{RESEARCH RATIONALE AND AGENDA}

This paper as a sequel to a preceding conceptual one by both authors, aims to contribute to bridging and evident research gap on how far making marketing research more philosophical through the science of logic can pay off, arguably, in terms of optimization of marketing performance indicators with special emphasis on marketing ROI. Theoretical analysis of annotated bibliographical literature on logic of marketing research process and deliverables along with subsequent meta-analysis of real marketing research reports are the main research methodologies adopted for this highly iterative agenda. The research concludes with developing a conceptual framework and research hypothesis which are empirically tested as illustrated to bridge the research gap. Accordingly, this research has relied on systematic theoretical analysis of annotated bibliographical review of literature on the genesis and recent advances of the science of logic and their argued interventions in the marketing research process. Additionally the same methodology has been followed to trace how this logic of marketing research could reflect on reaching higher levels of marketing ROI. Eventually, a meta-analysis of real marketing research reports is devised to test the research hypothesis with a view toward substantiating empirically how the extent of following various underlying dimensions of logic of marketing research can influence the optimization of marketing ROI within those specific marketing problems and opportunities tackled by the selected marketing research reports.

\section{INTRODUCTION- SCIENCE OF LOGIC}

In philosophy, the science of logic is the study and classification of the argument forms through which valid inferences can be made from premises. Logic is not concerned directly with the truth or falsity of statements, but rather with the relationships between them. One way of summarizing this, is to say that logic is about the rules for the correct use of the word " therefore" which involves the logical processes of deduction, induction, reproduction and transcendental argumentation (Benton \& Craib, 2001).

So far, philosophy has often referred to the disputes, disagreements, arguments and so on, which go on among philosophers and other social scientists. If the texts in which these disputes are conducted, are examined, stereotyping and caricaturing of one another views, outright misinterpretation, questioning of political motives, and allegation of bias and so on, will often be found evidently. While these philosophical topics might have a lot of rhetorical and persuasive force, they are not the same thing as good arguments. The discipline of logic is an attempt to set down in a systematic way what moves the difference between a good and a bad argument. When an argument is constructed, there is usually an attempt to show why a particular statement ("conclusion") should be accepted as true. In order to do this, researchers bring together other statements, which give an account of relevant evidence, or other 
considerations, which provide the grounds for believing the truth of the conclusions. These statements are the premises of the argument. A "valid argument" is one in which the conclusion follows from the premises. It is one in which anyone who accepts the premise must accept the conclusion. This does not mean that the conclusion itself must be true, only that it is as reliable or as well established as the premises from which it is derived (Ayer, 1946 \& Levy ,1959).

As a marketing research example:

If there is a change in price, customers will change their level of perceived quality. Therefore, customers use price as an indication of quality. This valid marketing argument, because of the conclusion does follow from the premises.

\section{RESEARCH GAP}

There is an evident and explicit research gap on associating investing in advanced and improving the front edge scientific foundations and frontiers of philosophical underpinnings of the marketing research process and tangible marketing performance outputs and deliverables so, this research is an endeavor to make both philosophical ends of marketing research and practical ends of marketing management meet. This research would strive to contribute to bridging this research gap by demonstrating how a deep philosophical innovation of inserting the science of logic into the marketing research process with all its intellectually rich insights and frontiers and conceptual tools could be argued to help significantly in posting a very seductive and yet very elusive down-to-earth marketing benchmark which is marketing ROI.

\section{AIM OF RESEARCH}

This research aims to reflect to extent careful devising of the philosophical rules of logic can have immediate and tangible impacts on marketing targets. So, an investigation is made on the potential influence of designing and adopting logic of marketing on the instrumental agenda of boosting marketing Return on Investment.

\section{RESEARCH METHODOLOGY}

The theoretical part of this research has relied on systematic theoretical analysis of annotated bibliographical review of literature on the genesis and recent advances of the science of logic and their argued interventions in the marketing research process. Additionally the same methodology has been followed to trace how this logic of marketing research could reflect on reaching higher levels of marketing.

The empirical investigation part that this paper has based its empirical analysis on the proposed conceptual framework has devised a meta-analysis of a nonprobability judgment sample of ten multiple cross sectional designed real marketing research reports to test the research hypotheses with a view toward substantiating empirically how the extent of following various underlying dimensions of logic of marketing research can influence significant benchmarks of marketing ROI within those specific marketing problems and opportunities tackled by the marketing research reports. Special forest-plots scales were developed for analysis purposes of ten real-state development marketing feasibility studies to measure the argued aspects of logic of marketing research for each report. By the same token, indicators of magnitude and direction of impacts of such levels of applied logic of marketing research on targeted marketing ROI for a specific marketing decision and performance management situation investigated by each marketing research report would be inferred relying on the statistical technique meta regression and its hypothesis testing deliverables. 


\section{THEORETICAL EXPLORATION AND EXTENSION OF PHILOSOPHY OF MARKETING LOGIC}

This view of the policy role of social science has continued to be very widely-held and it provides yet another justification for extending the logic and methods of the natural sciences into the study of marketing and other social sciences and vice versa. Only on the logical basis of the sorts of claims to quantitative reliability, objectivity and general applicability already made by natural sciences could the social science of marketing expect to be taken seriously by marketing policy-markers. Today in most countries official statistics with marketing implications are collected on virtually all aspects of social and economic life such as patterns of health and death, on marriage and divorce, on unemployment, income differentials attitudes and values, consumption patterns and so on, some marketing scholars as social scientists are employed by business, public and entities to collect and other research finding (Benton \& Craib, 2001).

Interpret these data, as well as to give advice on their marketing policy implications. This logical form of scientific explanation as represented in the empiricist "covering law" model shows how the link between such knowledge and marketing policy making might be made. To oversimplify considerably, the statistics might show that price sensitive behavior by customers was more common among younger market segments. This is not a universal law, but statistical generalization(though the required element of universality might be present if it is held that this statistical generalization holds across different marketing research contexts such as different cultures and historical periods of time. However, the basic structure of scientific explanation can be maintained: - (Gronroos, 2006 ,Gronroos \& Ravald, 2011, Vargo \&Lusch, 2005 \& Vargo \&Lusch, 2007).

If there are younger customers then there will be higher levels of price sensitivity. Therefore:there are higher levels of price sensitivity leading to higher levels of using price as an indicator of quality any the company is customer base. If marketing policy makers are convinced by marketing research logic that high rates of price sensitivity are a bad thing, and are changed with coming up with marketing policies to reduce them, then this piece of scientific explanation will yield the marketing policy recommendation to take marketing action to reduce price sensitivity levels.

Logically, there are some obvious complications there are is that a more statistical association between age groups and price sensitivity levels does not show that one causes the other. It could be that some third social fact, such as income levels causes both higher levels of price sensitivity and perceived quality. Marketing policy of dealing with income level categories among customers therefore might be more effective than trying to do something about younger customers and their price sensitivity levels. But there might be more subtle problems with the statistical association.

It might for example, be that the association of age group to price sensitivity is stigmatized by prevailing customer lifetime values. If this were so, then the appropriate marketing policy might be to work for a cultural shift in favor of more quality- sensitive customer lifetime values. However, more of this counts against the positivist ration of "marketing engineering" as such. Each of these limitations and pitfalls can principles of marketing research logic is addressed by more exact data-gathering, and more sophisticated and powerful analytical methods. There are, however other lines of criticism to positivistic logic of marketing research which will be explored in next sections of the paper. 


\section{MECHANISMS AND CONSEQUENCES OF MARKETING LOGIC}

Logical reasoning and creativity plays a critical role in the invention of theories by marketing research. Theories in marketing thought, are intended as plausible answers to ultimate ensures to marketing questions posed by reflection on already- acquired observation generalizations. The process whereby such answers are invented involves scientific marketing imagination and creativity. For this reason, empiricist philosophers of science tend to treat it as outside their sphere of concern, relegating it to the discipline of psychology.

As far as they are concerned, philosophy of science is focused only on such subject areas as the logical structure and openness to empirical testing of scientific theories once they have been inverted (the context of justification). Nevertheless, it is clear that something more can be said about the logic and more broadly, the sorts of reasoning involved in the invention of theories. For one thing, not just anything will count as a plausible marketing research candidate for marketing explanation. It might be proposed, for example, that the company's pricing policy result in the appropriate perceived quality rise, and signal to each customer that it is time to get on with new perceptions of quality. However, what is known about the implications of pricing policy and more generally about the psychology of price/quality sensitivity makes it unlikely that this sort of conscious regulation of buyer behavior activity. In this way, both background knowledge and experimental intervention can narrow down the range of plausible logical explanations of the marketing phenomenon (Kortam et al, 2012).

Moreover, even if plausible, a potential explanation would still have to satisfy a criterion of relevance. So, for example, someone might give the functional explanation of the role of price changes as a part of a marketing activity on levels of perceived quality to answer the historical narrative question about how these of price sensitivity based quality perceptions patterns become established in the population of the company's target market segments. However, it could for example be that the particular combination pf price sensitivity and perceived quality in the course of marketing evolution of this population provided optimal chances for meeting emerging customer profiles and needs and avoiding price combination of price sensitivity and perceived quality in the course of marketing evolution of this population provided optimal chances for meeting emerging customer profiles and needs and avoiding price competition. Selective pressures operate at the level of individual customer world. If this were true, be likely to result in even-closer approximation to emergence under these new demographic and psychographic conditions across the whole population over a number of generations of customers. The observed phenomenon of simultaneous emergence of price changes and levels of perceived quality would thus be contingent outcome of the spread through the population of an individual customer adaptation to environmental marketing conditions. So, there are constraints on the range of marketing inventions that can count as plausible candidates for theoretical explanations of marketing phenomena. In particular, the proposed explanation must refer to something which given the background knowledge could well be true. The philosopher of science (Hanson, 1965) has referred to the logic of this sort of creative work in science as "a conclusion in search of premises"; - it is known what the observed pattern of phenomena is, and what scientists are searching for is something that could have brought it about. (Hanson, 1965) followed by Pearce, 2005) calls this sort of logical reasoning logical reproductions distinct from deductive and inductive.

So, marketing researchers can see a certain logical pattern and an associated set of constraints on the invention of theoretical explanation in the science of marketing. Also, there are features of scientific reasoning which link it closely with creativity on other areas of science. The most discussed of these is the use of metaphor and analogy (Hessa, 2014). Scientists are familiar with the textbook diagrams of atoms as miniature solar systems, with a nucleus and orbiting 
electros. Darwin's theory of evolution makes use of an analogy between the practices whereby the breeders of domesticated animals and plants bring about changes by "selective breeding" and the action of environmental conditions in "selecting" which variants in a population in the wild survive and reproduce. The term "natural selection" embodies this metaphor Darwinism implications to marketing research are argued for through the processes of variation, selection and replications with important metaphors and analogies for marketing phenomena, insights and outlooks (Kortam \& Gad, 2014). The explanation of the role of DNA in the development of organisms involves thinking of the sequencing of molecular units on strings of DNA as a code carrying instructions for making different protein molecules which is also metaphoric and analogous to a proposed evolution process of marketing research in terms of an encoding, application and decoding phased configuration (Kortam, 2006, Kortam et al, 2012 \& Kortam \& Gad, 2014). Much more controversially some scholars of " cognitive science" like marketing commonly use the operation of computerized quantitative and qualitative analytical techniques to build their models for thinking about human cognitive processes such as price sensitivity and perceived quality(pinker,1997) which was also heavily criticized(GreenField,1997).

This feature of scientific creativity is also difficult to square with any strict version of empiricism. An imaginative leap is required to recognize that the observed pattern of marketing phenomena would be produced if some process analogous to one already understood in another discipline were at work. Since the source of the metaphor may be a mechanism or process outside science. As, for example with the idea of a genetic code, or of natural selection, the use of metaphors in the construction of scientific theories is an important link between marketing science and the wider cultural context which it belongs and within which it operates. This link is an important starting point for sociologists of science and other social scientists who argue that seemingly universal and objective scientific knowledge contains unacknowledged value commitments and culturally( context-specific) assumptions. This aspect of marketing as a science tells against the empiricist tendency to claim that marketing research is an objective science because it is exclusively the result of applying formal logical rules to feature evidence.

On the other hand, the use of metaphors in science does not necessarily justify the "reduction" of science to its cultural context (Benton 1995). Though it is important to recognize what other creative activities, such as cinema direction, have in common with scientific theorizing, it is also important to understand the different constraints in the development of analogical logical reasoning in science (Lopez 1999) to be acceptable, this paper argues that scientific analogies in marketing research have to satisfy requirements imposed by the scientific discipline of marketing phenomena which have been invented to explain and the further elaboration of a metaphor as it is subjected to experimental and observational testing may take it progressively further from its original formulation on its native scientific soil.

Consequently, the proclaimed universality of the concept of science is the point of argument in this regard. This is by no means uncontroversial in contemporary natural science, but in social sciences (with special reference to marketing research) it is still more problematic for reasons related to the scientific logic of social sciences. It is evident that forms of human social life and their cultural practices differ from place to place and time to time consequently, it follows that marketing research as a social science need to develop theories which are sensitive to specificity and difference. Nevertheless, in order to detect difference it is necessary to have at least some marketing concepts which span and transcend across the different cultures under scientific comparison by marketing researchers. It is argued that marketing researchers need 
some basic concepts of human universals like birth, death, labor, gender, social class nationality and religion will a view toward being able to make any logical sense of universality of marketing research-based scientific knowledge (Kortam \& Gad,2014 \& Vargo \& Lusch 2008).

\section{CONCEPTUAL MODEL}

So, based on the above theoretical analysis and deductive reasoning, it is proposed by this paper that logic in marketing research should consist of marketing soiled logical breaded postulates as independent variables and leading benchmarks as signaling indicators of marketing ROI and that the subsequently deduced hypothesis represent the argued configurations by the proposed model:

\section{Independent variable (logic of marketing Research)}

A- Core of marketing research logic :-

1. Premises of logic

2. Logical reasoning

3. Logical conclusions

B- Rigor of marketing Research logic:-

1. Logic based theoretical explanation

2. Logical critique and revisit of positivism and empiricism in marketing research

3. Logical analysis of marketing research

4. logical metaphors of marketing research

5. logical universality of marketing research

C- Breakthrough of Marketing Research logic

1. Inventions and creativity of logic

2. Logical imagination to rethink marketing research methodologies

\section{Dependent variables (Marketing ROI)}

A- Determination of marketing ROI:-

1. Manipulation of marketing ROI

2. Detecting the ROI potential areas of maximization and priorities.

3. Revealing ROI benchmarks to be reached

B- Precision of marketing ROI:-

1. Identifying which existing marketing theories can be used to understand the logical mechanism process underlying a specific marketing ROI.

2. Determining when is positivism research and empirical evidence can be used to support new ways or existing ways to increase marketing ROI

3. Determining which steps of marketing research process can be adapted to come up with appropriate logical pathways to boost marketing ROI

4. Determining the logical manifestations and connotations that can be translated into profitability drives of marketing ROI.

5. Spotting significant commonalities and reconceptualization that produce transcending marketing knowledge across several contexts which should lead to more pervasive and sustainable marketing ROI.

C- Perpetual optimization of marketing ROI:-

1. Higher return and lower investment

2. Expression of the possible innovative marketing ROI that results from outside-thebox logic that can be used to revolutionize new paradigms of marketing research methodologies. 


\section{Research hypothesis:-}

H1:- there is a significant and positive impact of core of marketing research logic on determination of marketing ROI.

H2:- there is a significant and positive impact of rigor of marketing research logic on precision of marketing ROI.

H3:- there is a significant and positive impact of breakthroughs of marketing research logic on perpetual optimization of marketing ROI.

\section{Empirical investigation:-}

This research as above indicated, adopted meta-analysis as the main statistical tool for measurement, scaling and data collection. Meta-analysis is a relatively new tool for advanced marketing research purposes. It is a set of procedures for statistically synthesizing the methodologies and results of the selected sample of the ten marketing research reports reflecting variations of logic of marketing research and marketing ROI. Meta-analysis is some sort of research on research and it is adopted by this research because there is an aim to examine the body of evidence about the impact of logic of marketing research on marketing ROI, rather than relying on the results of a single positivistic study. The rigorous use of metaanalysis provides a systematic way to investigate a collection of findings, typically effect sizes across the multiple (ten ) pervious marketing research studies. It also steeds light on factors potentially causing dissimilarities in findings and help to make sense of the patterns of impacts of logic of marketing research on marketing ROI. Meta-analysis was also found to be appropriate for this research agenda, because the ten primary marketing research studies are judged as not too disparate. Since real impacts can not be reliably established through one marketing research report alone, meta-analysis permitted a better estimate of the true size of influences of logic of marketing research on marketing ROI. Impact sizes were measured for this research by means, proportions, risk ratios, odd ratios or correlations. Meta-analysis was not simply used as a computational process for adding up impact sizes in each marketing research report and dividing by the number of reports under empirical investigation. Also, it was not used for just counting the number of significant differences favoring one strength and direction of one hypothesis on another to support pre-held dispositions. Instead, meta-analysis was devised to use statistical techniques as forest plots and meta-regression to combine the results of all ten marketing research reports. Ideally, data from individual underlying dimensions that are used to configure logic of marketing research and marketing ROI in each report was used to analyze aggregated of all ten reports simultaneously.

For meta-analysis of collected data, the individual reports are weighted by precision, which is derived from the standards errors of the ten marketing research reports. The term inverse variance is used to express this weighting mechanism as a statistical adjustment of primary data. This inverse variance is mainly a function of sample size. The ten marketing research reports selected as a sample size was decmed adequate as influential in meta-analysis of the impacts of logic of marketing research on marketing ROI. It was not essential that all marketing research reports in a meta-analysis measured the impact of logic of marketing research on marketing ROI in the same way. The adequacy of the sample size justified the use of forest plots and meta-regression that employ formulas to convert among impact sizes based on dissimilar metrics of the causal relationship between the underlying dimension of logic of marketing research as the independent variables and marketing ROI as the dependent variable. Results of meta-analysis were normally summarized with forest plots which is a graphical device that efficiently reflects the highlights of the analysis of both independent and dependent variables. The term "forest" stands for "forest" of lines. This paper argues to be interested in both the trees of logic of marketing research and marketing ROI and the forest of their causal 
impacts. Table (1) depicts the aggregated measurements of the three independent variable and the three dependent variable across the selected ten marketing research reports.

Table 1:- Forest plot of logic of marketing research and marketing ROI impact sizes (Ratio scales of ten marks)

\begin{tabular}{|c|c|c|c|c|c|c|c|c|c|c|c|}
\hline & Studies & \multicolumn{10}{|c|}{ Marketing Research Reports } \\
\hline & Variable & 1 & 2 & 3 & 4 & 5 & 6 & 7 & 8 & 9 & 10 \\
\hline 1 & Core of logic & 5.4 & 7.2 & 5.3 & 6.2 & 3.1 & 9.1 & 8.1 & 5.6 & 5.8 & 6.2 \\
\hline 2 & Rigor of logic & 8.6 & 7 & 6.3 & 3.2 & 4.5 & 6.5 & 7.2 & 7.3 & 9.1 & 3.6 \\
\hline 3 & Breakthroughs of logic & 3.4 & 5.5 & 2.1 & 1.7 & 3.1 & 4.4 & 5.2 & 5.6 & 3.2 & 3.9 \\
\hline 4 & ROI Determinates & 5 & 6.8 & 5.5 & 5.7 & 3.3 & 9.5 & 7.7 & 5.8 & 6 & 6 \\
\hline 5 & ROI Precision & 8.2 & 6.7 & 6 & 3.6 & 4.3 & 6.3 & 7 & 7.5 & 8.7 & 2.8 \\
\hline 6 & $\begin{array}{l}\text { ROI Perpetual } \\
\text { maximization }\end{array}$ & 3.2 & 5.1 & 1.6 & 2 & 3 & 4 & 4.7 & 5 & 3.5 & 3 \\
\hline
\end{tabular}

Multiple regression is widely used in primary marketing research and also has an important role in meta-analysis. Rather than subjects in one primary report, nevertheless, observations in the meta-regression data input file are the results of the logical profiles of their methodologies. Independent variables and dependent variables are estimated of the marketing research report level, not the subject (e.g., respondent) level. As in the case of standard regression, independent variables were either continuous, categorical or a blend of both data profiles. Fixed and random impacts of logic of marketing research on marketing ROI were both evident, as are variations of regression (e.g., polynomial and logistic). Analogous to regression for positivistic primary purposes, the number of marketing research reports should be sufficiently large for meaningful analysis. Therefore, Bagozzi, et al (2016) has argued for a minimum of ten pieces of research per dependent and independent variables for meta regression purposes as a rule of thumb, though this sample size is not set in store. Table (2) depicts the output results of meta-regression for hypothesis testing to attain the aim of this research.

Table (2) Meta-Regression output for hypothesis testing

\begin{tabular}{|c|c|c|c|c|c|c|c|}
\hline \multirow[t]{2}{*}{ Equation } & \multirow{2}{*}{$\begin{array}{l}\text { Dependent } \\
\text { variable }\end{array}$} & \multicolumn{3}{|c|}{ Independent variables } & \multirow{2}{*}{ Adjusted R } & \multicolumn{2}{|c|}{$\mathrm{F}$} \\
\hline & & $\begin{array}{c}X 1 \\
\beta(\operatorname{sig} t, t)\end{array}$ & $\begin{array}{c}X 2 \\
\beta(\operatorname{sig} t, t)\end{array}$ & $\begin{array}{c}X 3 \\
\beta(\operatorname{sig} t, t)\end{array}$ & & Sig. $\mathrm{f}$ & $\mathrm{F}$ \\
\hline one & Y1 & $\begin{array}{c}3.3 \\
(0.5,3.6) \\
\end{array}$ & $\begin{array}{c}1.2 \\
(0.8,1.3) \\
\end{array}$ & $\begin{array}{c}1.8 \\
(0.1,0.72)\end{array}$ & 0.521 & 1.3 & 7.7 \\
\hline two & Y2 & $\begin{array}{c}2.8 \\
(1.1,3.4)\end{array}$ & $\begin{array}{c}4.1 \\
(0.3,4.2)\end{array}$ & $\begin{array}{c}3.1 \\
(0.8,2.1)\end{array}$ & 0.563 & 0.3 & 3.6 \\
\hline three & Y3 & $\begin{array}{c}3.1 \\
(0.5,0.75)\end{array}$ & $\begin{array}{c}3.7 \\
(0.6,1.2)\end{array}$ & $\begin{array}{c}5.7 \\
(0.3,4.2)\end{array}$ & 0.655 & 0.4 & 5.2 \\
\hline
\end{tabular}

$\mathrm{Y} 1=\mathrm{X} 1+\mathrm{X} 2+\mathrm{x} 3$

$\mathrm{Y} 2=\mathrm{X} 1+\mathrm{X} 2+\mathrm{X} 3$

$\mathrm{Y} 3=\mathrm{X} 1+\mathrm{X} 2+\mathrm{X} 3$

Such that; 
$\mathrm{X} 1$ Core of logic

$\mathrm{X} 2$ Rigor of logic

X3 Breakthroughs of logic

Y1 ROI Determinates

Y2 ROI Precision

Y3 ROI Perpetual maximization

\section{HYPOTHESIS TESTING AND CONCLUSIONS}

Three meta regression equations were developed to reflect how far each of the logic of marketing research factors influenced the level of each indicator of marketing ROI.A full entry mode of all three factors of logic of marketing research was followed to infer which of them emerged as the most significant and influential determinant for each of the three key indicators of marketing ROI.

The F statistics show that all three meta regression equations exhibit a relatively high level of fitness model which means that logic of marketing research does have a genuine effect on marketing ROI in general.

The forest plots, B values and t statistics make a clear inference that all three hypothesis can not be rejected. There was an obvious evidence the core factor of logic of marketing research has the largest and most significant magnitude of impact on the determination indicator of marketing ROI. The same results are strongly evident for the impacts of the rigor factor of logic of marketing research on the precision indicator of marketing ROI alongside the impact of the breakthrough factor of logic of marketing research on the perpetual maximization indicator of marketing ROI. Nevertheless the rest of the B values and t statistics clearly indicate that the other two factors of logic of marketing research are also significant determinants of the designated indicator of marketing ROI but to a less extent.

Finally, the coefficient of determination for each meta regression equation implies an alarming conclusion as far as the explanatory power of logic of marketing research on marketing ROI is concerned. The breakthrough factor of logic of marketing research explains most the perpetual maximization of marketing ROI with the other two factors followed by the rigor and core factors of logic of marketing research' explanation of the precision and determination indicators respectively. This makes explicit expression of evident multicollinearity and intersection effects among all underlying dimensions of logic of marketing research and marketing ROI. The absence of any intercept value for all three meta regression equations is a clear reference to the ultimate question of whether it pays off to be philosophical when devising marketing research as an opportunity seizer, problem solver and genuine source of marketing-based competitive advantage. These two final conclusions paves a way for future research on the effect of various conceptualization of logic of marketing research on various contributions of marketing.

Braver frontiers if marketing scholars hold a strong belief in making marketing research more effective through a quantum leap of making it deliberately and geometrically philosophical, are:

- Inaugurating a Socratic school of marketing thinking for argumentation (Elenchus in ancient Greek)

- Devising a Descartes' critical rationalism as new discourse of marketing research methodology (Discourse de la method). 
- Developing an Einstine's analogy of a general relativity theory of marketing through the marketing dualistic metaphors of place, time, man and mass.

\section{References}

Arnould,J Eric (2015). Service-dominant logic and consumer culture theory: Natural allies in an emerging paradigm. Research in Consumer Behavior. Marketing Theory, Vol 11, pp 57-76.

Ayer, A.J (1946). Language truth and logic. London: Gollancz.

Bagozzi, R., Kortam, w. , Refai, R., and Mahrous, A., (2016) , " the journey from consumers to co-creations:Exploring consumers' co- creation experiences by means of neurophysiological marketing research " marketing management association conference, Chicago, USA.

Benton, T (1995). From castaways to throwaways: marine litter in the Pitcairn Islands. Biological. Journal of the Linnean Society. Vol 56, Iss 1-2. pp 415-422.

Benton, T (1995). Science, Ideology and Culture: Malthus and the Origin of species' in Amigoni, D. and Wallance, J.(eds) Charles Darwin's Origin of Species: New interdisciplinary Essays. Manchester University.

Benton, T. and Craib, I (2001). Philosophy of Social Science: The Philosophical Foundations of Social Thought, New York: Palgrave.

Greenfield, S (1997). The Human Brain: A Guided Tour. London: Weidenfeld and Nicolson.

Gronroos, Christian and Ravald, Annika (2011).Service as business logic: implications for value creation and marketing. Journal of Service Management, Vol. 22, Iss: 1, pp.5 - 22.

Gronroos, Christian (2006). what can service logic offer marketing theory? In Lusch F, Robert and Vargo, L Stephen. The Service-dominant logic of marketing: Dialog, debate, and directions (pp. 354-364).

Hanson, N.R (1965). Patterns of Discovery. Cambridge University Press.

Hassan, Salah S, Craft, Stephen and Kortam, Wael, (2003), Understanding the new bases for global market segmentation", Journal of Consumer Marketing, Vol. 20, Iss: 5, pp.446- 462.

Hessa A. Alghadeer (2014). Digital Landscapes: Rethinking Poetry Interpretation in Multimodal Texts. Journal of Arts and Humanities.Vol 3, Iss 2.pp 87-96.

Kortam, Wael (2006). Adaptability of Marketing Research to Service Industries: The Role Encoding, Application and Decoding Phases, The case of Egyptian Bank. International Journal of Business Research, Cairo University Press, PP: 86 - 106.

Kortam, Wael and Gad, Ghada (2014). Generalized Darwinism For An Evolution Theory of Marketing Research: Survival For The Fittest of Marketing Knowledge, Proceedings of The Marketing Research Summit, Marketing Edge Organization, San Diego, California, USA.

Kortam, Wael, Mahrous, Abeer and Attia, Sarna (2012). Developing a Theory of Ubiquitous Marketing Research: Combining Ideology and Methodology of Marketing Research. Journal of American Science. Vol 8, iss 4, pp 534538.

Levy J, Sideny (1959). Symbols for sale. Harvard business Review, Vol 37,pp 117-124.

Lopez, J. (1999). The Discursive Exigencies of Enunciating the concept of Social Structure: Five Case Studies. Unpublished PhD thesis, University of Essex.

N.R. Hanson (1965). Were the eye not attuned to the Sun, the Sun could never be seen by it. Cambridge University Press.

Pearce, David (2005) .Reasoning with Negative Information, II: Hard Negation, Strong Negation and Logic Programs, Technical Report, Gruppe Logik, Wissenstheorie und Information Institute for PhilosophyFreie Universität BerlinBerlin 33.

Pinker, S. (1997) How the Mind Works. Harmondsworth : Penguin.

Stewart W, David (2009). Marketing accountability: Linking marketing actions to financial results. Journal of Business Research. Vol 62, Iss 6,pp 636-643.

Smyth, Hedley. Lecoeuvre, Laurence (2015). Differences in decision-making criteria towards the return on marketing investment: A project business perspective. International Journal of Project Management. Vol 33, Iss 1, pp 29-40. 
Kortam, W., \& Gad, G. (2020). The Impact of Logic of Marketing Research on Marketing ROI: Theoretical Analysis and Empirical Investigation. Archives of Business Research, 8(1), 152-162.

Vargo ,L Stephen .and . Lusch F,Robert (2005)" Evolving to a New Dominant Logic for Marketing. Journal of Marketing: January 2004, Vol. 68, No. 1, pp. 1-17.

Vargo ,Stephen L.and . Lusch ,Robert F \& O'Brien, M. (2007). Competing through service: Insights from servicedominant logic. Journal of Retailing, vol 83, iss(1),pp 5-18.

Vargo L ,Stephen .and . Lusch F ,Robert (2008) " Service-dominant logic: continuing the evolution", journal of the academy pf marketing science, Vol.36. Iss 1, pp.1-10. 